\title{
Protection of Steel Corrosion in Concrete Members by the Combination of Galvanic Anode and Nitrite Penetration
}

\author{
Minobu Aoyama, ${ }^{1}$ Shinichi Miyazato, ${ }^{2}$ and Mitsunori Kawamura ${ }^{3}$ \\ ${ }^{1}$ Department of Maintenance Engineering, Central Nippon Highway Engineering Nagoya Co Ltd, Kanazawa Branch, \\ Ekinishi Honmacthi, Kanazawa, Ishikawa 920-0025, Japan \\ ${ }^{2}$ Department of Civil and Environmental Engineering, Kanazawa Institute of Technology, Hakusan, Ishikawa 924-0838, Japan \\ ${ }^{3}$ Kanazawa University, Kakumamachi, Kanazawa, Ishikawa 920-1192, Japan
}

Correspondence should be addressed to Minobu Aoyama; m.aoyama.a@c-nexco-hen.jp

Received 7 August 2013; Accepted 22 December 2013; Published 12 February 2014

Academic Editor: Flavio Deflorian

Copyright (C) 2014 Minobu Aoyama et al. This is an open access article distributed under the Creative Commons Attribution License, which permits unrestricted use, distribution, and reproduction in any medium, provided the original work is properly cited.

Chloride induced-corrosion of steel bars in concrete can make cracks and exfoliation in near-surface regions in reinforced concrete structures. In this paper, we described the basic concept and practice of steel bars corrosion protection method by the combination of galvanic anode (zinc wire) and the penetration of nitrite ions from mortar layers containing a large amount of lithium nitrite.

\section{Introduction}

The effectiveness of nitrite compounds as an admixture to prevent steel bars from corroding in concrete containing chloride ions is generally well documented [1-5]. However, there is still little attempt to prevent the corrosion of steel bars by the penetration of nitrite ions from the outside to hardened concrete with relatively large amounts of chloride ions except that Ngala et al. [3] assessed the efficiency of calcium nitrite as an inhibitor when used in surface treatment.

We found many RC slabs with cracks which had been caused by externally supplied chloride-induced corrosion of steel bars. The slabs were partly exfoliated on their surfaces. In these concrete members, steel bars were arranged perpendicular to each other in near-surface regions. Steel bars situated on the surface side severely corroded, but those on the inner side were not so significantly damaged. In the repair works of such damaged RC members, spaces left behind when concrete with large amounts of chloride up to the depth of corroded steel bars was removed have been filled with sufficient amounts of nitrite-containing mortars. The repair method is based on the expectation that supply of nitrite ions from the mortars can inhibit corrosion of steel bars situated at inner positions. However, the movement of nitrite ions through hardened concrete is very slow. Hence, it takes long time for sufficient amounts of nitrite ions to move from the mortars to old concrete. Then, we proposed the combined corrosion protection method of the nitrite penetration and the galvanic anode. Namely, in the method, a galvanic anode process was applied to steel bars by the use of zinc wires until sufficient amounts of nitrite ion reached the steel bars situated at inner positions. This composite method has an advantage that we can economically apply it to reinforced concrete members with large amounts of chloride ions brought from the outside over long times. However, it should be noted that good workability was required for the mortars when mixed with large amounts of a corrosion inhibitor. From this point of view, we used lithium nitrite as a corrosion inhibitor. In this paper, various experimental results to give assurance for the realization of this method were provided. Moreover, the actual execution of works and the specific design method to be implemented for the application of this technical method are also described.

\section{Characteristics of Corrosion Progress of Steel Bars}

2.1. Corrosion Condition of Steel Bars in the Bridge Slabs. The corrosion of steel bars in the bridge slabs in the expressway 


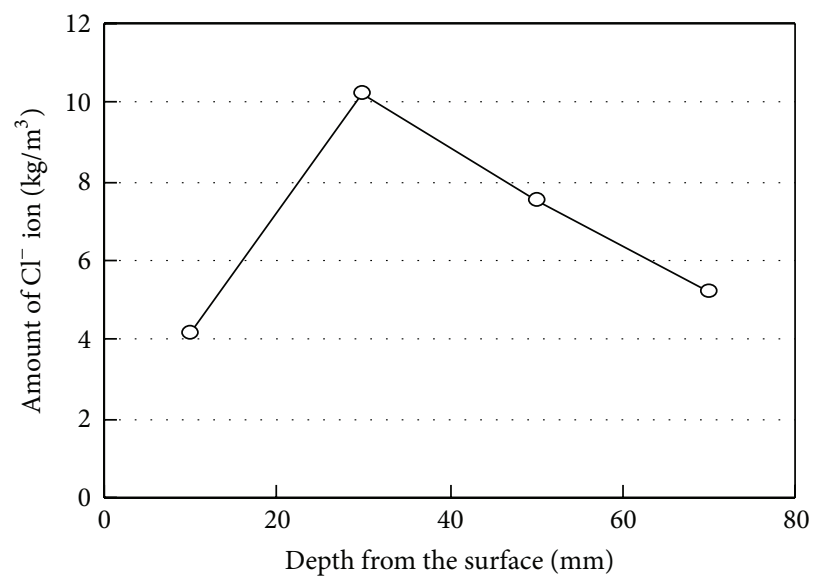

FIGURE 1: Distribution of chloride ion concentration in the regions near the under surface of RC bridge slabs deteriorated by the penetration of deicing salt.

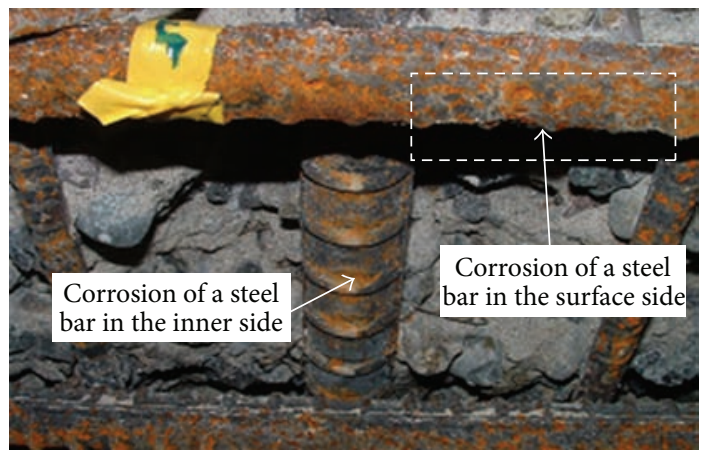

FIGURE 2: Actual situations of corrosion of steel bars in the vicinity of the under surface in a bridge slab.

was caused by the penetration of chloride deicers. Figure 1 shows changes in chloride ion concentration with the depth from surfaces in the vicinity of the under face of deteriorated decks at the edge of the RC bridge. Concrete covers were exfoliated in places around the portions. As seen in this figure, chloride ion concentration had reached the highest value around steel bars in most bridge slabs. From infiltration conditions of chloride ions in the bridge slabs, steel bars in concrete were under severe saline atmospheres even in the inner portions. However, corrosion concentrated on steel bars in the surface side; those in the inner portions only slightly corroded, as shown in Figure 2.

\subsection{Experiments for Confirming the Formation of Macrocells} in Steel Bars. In order to clarify mechanisms of differences in the degree of corrosion between steel bars in the surface and the inner side in near-surface regions in the bridge slabs, an experiment was conducted simulating the actual situations of steel bars in the process of degradation [6] (Figure 3). After mortar specimens (water/cement rate $=0.5$ ) were submitted to immersion in $\mathrm{NaCl}$ solution-drying repetitions, the total corrosion current density passing through the steel bars in the specimens was measured.

As shown in the upper part in Figure 3, steel bars $(13 \mathrm{~mm}$ in diameter) were halved in the longitudinal direction and then embedded in mortar specimens $(125 \times 125 \times 35 \mathrm{~mm})$ so as to perpendicularly intersect one another. Concrete cover in no. 1 , no. 2 , and no. 3 specimens is $5 \mathrm{~mm}$ thick and in no. 4 it is $0 \mathrm{~mm}$. In order to produce various stages of the degree of corrosion of steel bars, in no. 3 specimen, a slit of $0.2 \mathrm{~mm}$ in width is made in concrete cover, and, in no. 4 specimen, steel bars were directly exposed to corrosive conditions. Faces in concrete prisms except the under face $(125 \times 125 \mathrm{~mm})$ (Figure 3) were sealed with the epoxy resin, and then the concrete prisms underwent immersion in $\mathrm{NaCl}$ solutiondrying repetitions for 3 months (immersion in $3 \% \mathrm{NaCl}$ solution for 3 days, exposure to an $60 \%$ R.H. atmosphere for 4 days at $20^{\circ} \mathrm{C}$ ). At a week after the completion of immersion in $\mathrm{NaCl}$ solution-drying repetitions, the total corrosion current density between each element in steel bars was measured.

Figure 4 shows the maximum values of the total corrosion current density between each part in divided steel bars at various corrosion states. From this figure, progression rate of corrosion at the upper half in steel bars is different from that at the lower half. As seen in Figure 4, in the specimen no. 4 without concrete cover and the specimen no. 3 with a slit in concrete cover, corrosion rapidly proceeded in steel bars situated on the surface side but slowly did in the other part (H (2), N (1), N (2)). However, large amounts of chloride ions were present in concrete around these steel bars. These results 

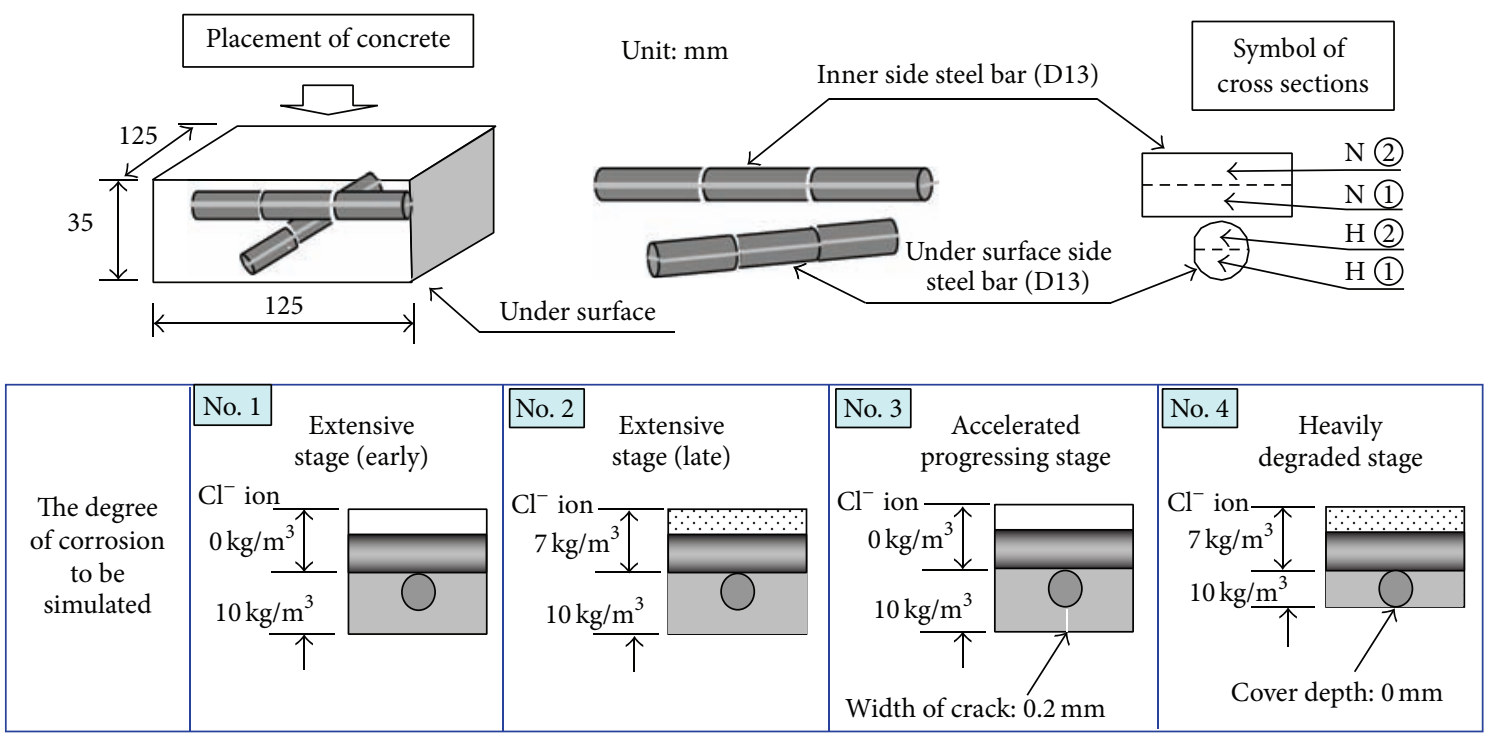

FIGURE 3: Measurements of current density in steel bars with progressing degree of corrosion.

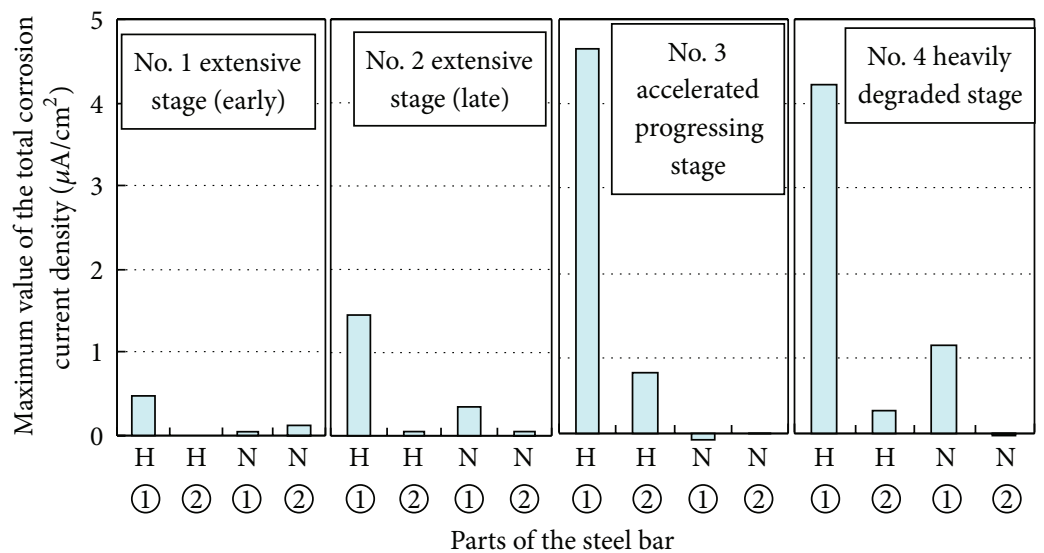

FIGURE 4: Average value of the total corrosion current density between each divided part in steel bars at various stages of corrosion state.

suggest that macrocells composed of the half of a steel bar in the surface side as the anode (H (1) ) and the other half and the inner steel bars as the cathode (H (2), N (1), N (2)) were formed. In bridge slabs damaged by externally supplied chloride, half of steel bars situated on the surface side are supposed to become the anode; the other half of the steel bars and steel bars in the inner side are supposed to become the cathode. As a result, the half of steel bars as the galvanic anode situated on the surface side severely corroded. Namely, large amounts of chloride ions have penetrated into deep portions in bridge slabs, but the degree of corrosion in steel bars situated in the inner portions was slight.

\section{Effectiveness of Corrosion Inhibitor-Containing Mortar Layers}

3.1. Effects of Lithium Nitrite on the Corrosion of Steel Bars and the Movement of $\mathrm{NO}_{2}{ }^{-}$Ions from Mortars to Concrete. In order to apply the combined corrosion control method to actual concrete structures damaged by steel corrosion due to chloride ions externally supplied, it is important to confirm whether externally supplied nitrite ions have corrosion inhibitive effects on steel bars in chloride-containing concrete. It is also necessary to quantitatively examine a critical $\mathrm{NO}_{2}{ }^{-} / \mathrm{Cl}^{-}$molar ratio to suppress the corrosion of steel bars in the concrete.

In this study, the accelerated indoor and outdoor exposure tests were conducted to discuss these subjects [7]. As shown in Figure 5, in the former exposure tests, $200 \times 400$ $\times 150 \mathrm{~mm}$ concrete specimens were used; in the latter $200 \times$ $800 \times 150 \mathrm{~mm}$ ones, $\mathrm{NaCl}$ was added to concrete to simulate externally supplied chloride-containing concrete. Concrete specimens $\left(W / C=63 \%, C=210 \mathrm{~kg} / \mathrm{m}^{3}\right)$ were composed of two parts with low and high $\mathrm{Cl}^{-}$ion contents of $2.5 \mathrm{~kg} / \mathrm{m}^{3}$ and $7 \mathrm{~kg} / \mathrm{m}^{3}$ (Figure 5). In both of the exposure tests, two types of specimens with and without a corrosion inhibitor $\left(\mathrm{LiNO}_{2}\right)$ were used, and in the other specimen, a thin mortar layer $20 \mathrm{~mm}$ thick containing a large amount of $\mathrm{LiNO}_{2}$ of $57.5 \mathrm{~kg} / \mathrm{m}^{3}$ was applied to the half part of top faces in a corrosion inhibitor-free concrete specimen. The molar ratio 


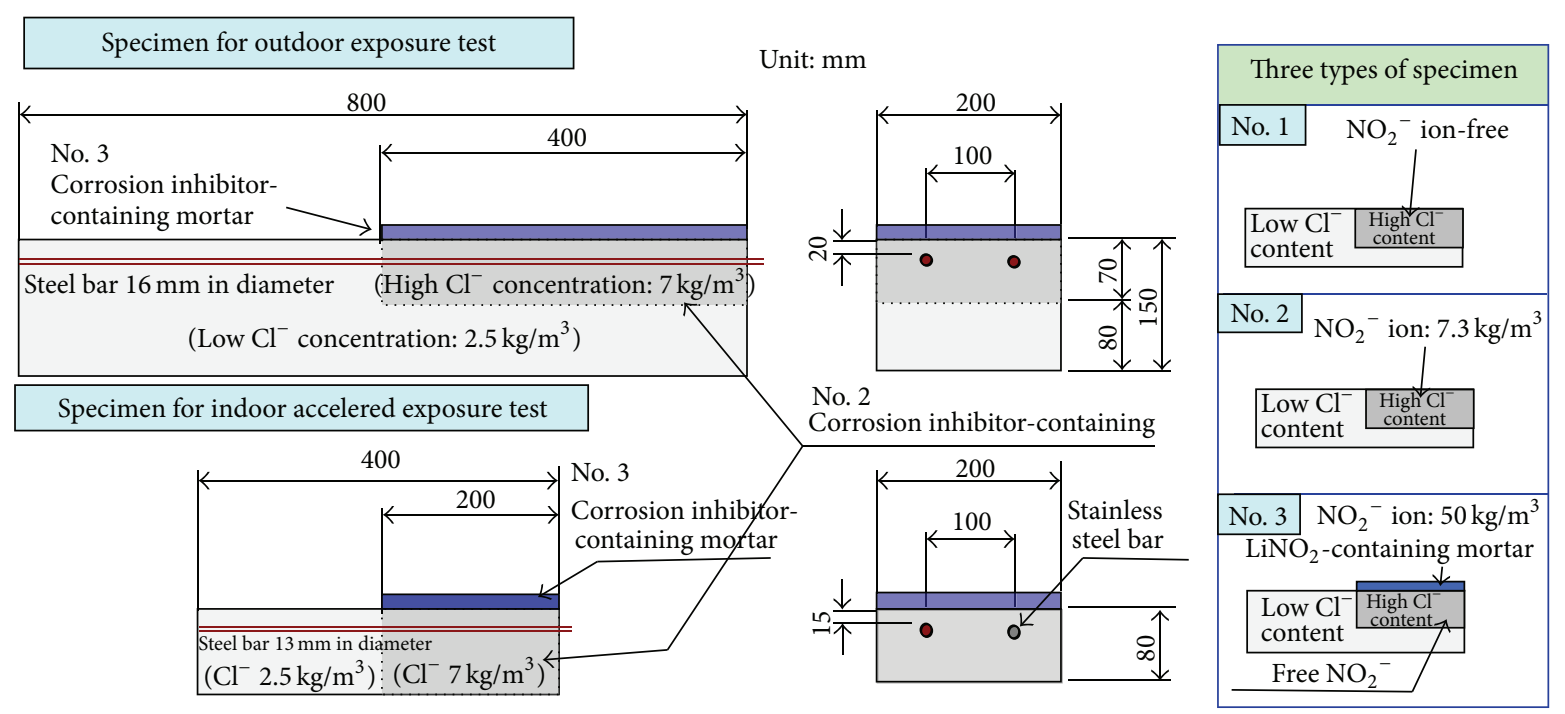

FIGURE 5: Specimens for the outdoor and the indoor exposure tests.

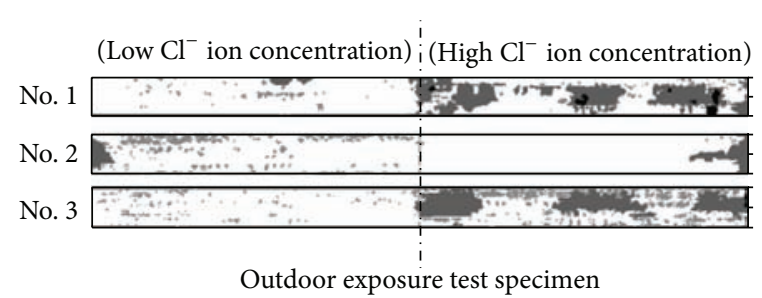

State of corrosion
Slight
Moderate
Severe

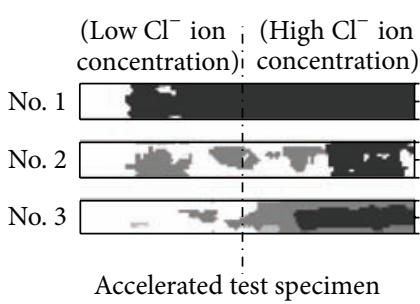

Accelerated test specimen

Figure 6: States of corrosion on steel bars after the completion of exposure tests.

of $\mathrm{NO}_{2}{ }^{-} / \mathrm{Cl}^{-}$in the $\mathrm{LiNO}_{2}$ and $\mathrm{NaCl}$-containing concrete was 0.8 . Steel bars were embedded in near-surface regions on the top faces.

The large specimens were exposed to outdoor environments for 37 months; the small ones wetting-drying repetitions (drying in $50 \%$ R.H. for 4 days and wetting in $>95 \%$ R.H. for 3 days at $40^{\circ} \mathrm{C}$ ) for 10 months in the laboratory.

Figure 6 shows the states of corrosion of steel bars in concrete after the exposure tests. It is found from this figure that, in $\mathrm{LiNO}_{2}$-containing concrete specimens with a large amount of $\mathrm{Cl}^{-}$ion $\left(\mathrm{NO}_{2}{ }^{-} / \mathrm{Cl}^{-}\right.$molar ratio of 0.8 ) (no. 2 specimen), corrosion of steel bars is considerably suppressed as compared to inhibitor-free specimens. Moreover, a comparison in the state of corrosion between no. 1 and no. 3 specimen in the accelerated tests clearly indicates that the addition of $\mathrm{LiNO}_{2}$ suppressed the corrosion of steel bars even in concrete with a large amount of $\mathrm{Cl}^{-}$ion. In particular, it should be noted that the application of a thin mortar layer with a large amount of $\mathrm{LiNO}_{2}$ to the top faces of concrete specimens (no. 3 specimen) suppressed the corrosion of steel bars. This fact suggests that $\mathrm{NO}_{2}{ }^{-}$ions penetrated from the mortar into concrete to considerable extent. In fact, judging from a distribution of $\mathrm{NO}_{2}{ }^{-}$ion concentration in the depth direction measured in no. 3 specimen exposed to outdoor environments (Figure 7), we can prove that $\mathrm{NO}_{2}{ }^{-}$ions in the mortar gradually penetrated into the concrete.

From the test results stated above, it is certain that the replacement of concrete with mortars containing $\mathrm{NO}_{2}{ }^{-}$ions could suppress the corrosion of steel bars surrounded by old concrete with large amounts of $\mathrm{Cl}^{-}$ions. Furthermore, corrosion inhibitive atmospheres will be formed around steel bars in concrete members in corrosive saline environments when a thin mortar layer with a large amount of $\mathrm{LiNO}_{2}$ is applied to their surfaces.

3.2. Quantitative Evaluation of Permeability of $\mathrm{NO}_{2}{ }^{-}$Ion. In order to design the repair works by the application of a thin mortar layer with a large amount of corrosion inhibitor to surfaces of hardened concrete including $\mathrm{Cl}^{-}$ions, it is necessary to quantitatively evaluate the permeability of $\mathrm{NO}_{2}{ }^{-}$ion from the mortars to concrete.

Outdoor exposure tests were conducted using $200 \times$ $130 \times 500 \mathrm{~mm}$ concrete prisms for quantitatively evaluating the penetration rate of $\mathrm{NO}_{2}{ }^{-}$ion from $\mathrm{LiNO}_{2}$-containing mortar layers to hardened concrete. As shown in Figure 8, concrete prisms with $\mathrm{LiNO}_{2}$-containing mortar layers $20 \mathrm{~mm}$ 


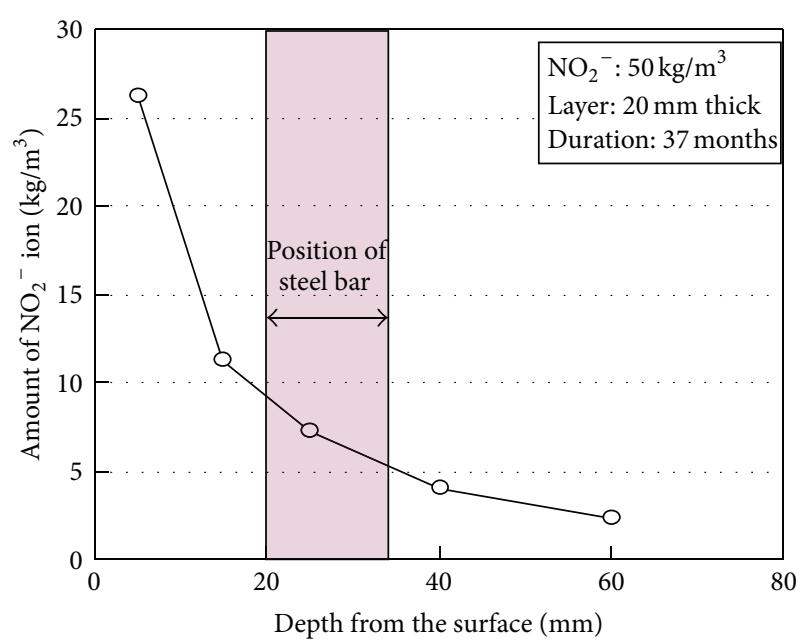

FIgURE 7: Distribution of $\mathrm{NO}_{2}{ }^{-}$ion concentration in the concrete specimen attached with a thin mortar layer containing a large amount of $\mathrm{LiNO}_{2}$ exposed to outdoor environments.

thick on the top faces were exposed to natural environments about $5 \mathrm{~km}$ from the coast for 37 months. The mix proportions of concrete and mortar used in the exposure tests are water/cement ratio of $50 \%$ (unit cement content $=$ $\left.342 \mathrm{~kg} / \mathrm{m}^{3}\right)$ and $45 \%($ sand $/$ cement ratio $=2.5)$, respectively. Steel bars $16 \mathrm{~mm}$ in diameter were embedded to simulate actual reinforced concrete. Two types of mortars containing chloride and nitrite ions of $50 \mathrm{~kg} / \mathrm{m}^{3}$ were used in mortar layers on the top faces of concrete prisms for comparing the penetration rate of $\mathrm{NO}_{2}{ }^{-}$and $\mathrm{Cl}^{-}$ions. Actually, as shown in Figure 8, mortars layers $20 \mathrm{~mm}$ thick were applied on a half of the top face of a concrete specimen $(200 \mathrm{~mm} \times 500 \mathrm{~mm})$. After that, other five faces of concrete specimens except under faces were sealed with the epoxy resin. Only the under faces of concrete prisms were exposed to natural environments for 37 months. Figure 9 shows $\mathrm{NO}_{2}{ }^{-}$and $\mathrm{Cl}^{-}$ion profiles at the end of exposure tests. As seen in this figure, both the ions in mortar layers gradually intruded into concrete. It is also found from this figure that $\mathrm{NO}_{2}{ }^{-}$ions in the mortars more rapidly moved into concrete than $\mathrm{Cl}^{-}$ions did.

Values of apparent diffusion coefficient $(D)$ were calculated by the finite difference method using $\mathrm{NO}_{2}{ }^{-}$and $\mathrm{Cl}^{-}$ion contents in concrete measured at various depths at the end of exposure tests (37 months). Five faces except the under face were sealed by the epoxy resin. Hence, the total amounts of $\mathrm{NO}_{2}{ }^{-}$and $\mathrm{Cl}^{-}$ions within concrete specimens did not change during and even after the exposure tests. $D$ values of $\mathrm{NO}_{2}{ }^{-}$ and $\mathrm{Cl}^{-}$ion calculated using the profiles of both the ions in the concrete prisms (Figure 9) were $4 \times 10^{-8} \mathrm{~cm}^{2} / \mathrm{s}$ and $3.3 \times$ $10^{-8} \mathrm{~cm}^{2} / \mathrm{s}$, respectively. Thus, $D$ value of $\mathrm{NO}_{2}{ }^{-}$ion is higher than that of $\mathrm{Cl}^{-}$ion. Therefore, even if the diffusion coefficient of $\mathrm{NO}_{2}{ }^{-}$ion is assumed to be the same as that of $\mathrm{Cl}^{-}$ion in the prediction of penetration of $\mathrm{NO}_{2}^{-}$ions from mortars layers into concrete in the design of practices, the assumption is on the safe side.

\section{Confirmation of the Effectiveness of Zinc Wire as a Galvanic Anode}

4.1. Exposure Tests. As shown in Figure 10, supposing the repair of concrete members in a saline environment, the specimens in which zinc wires as a galvanic anode were arranged along steel bars were exposed to accelerated exposure tests. The corrosion mitigation effect of the zinc wires was evaluated by measuring the total corrosion current density passing through steel bars [8]. Steel bars in concrete specimens (200 $\times 150 \times 350 \mathrm{~mm}$ ) were halved in the longitudinal direction. Two steel bars (13 $\mathrm{mm}$ in diameter) situated on the exposed face side and the other one (19 $\mathrm{mm}$ in diameter) in the inner portions were embedded to perpendicularly intersect each other. The thickness of concrete cover of the specimens is $0 \mathrm{~mm}$. The chloride ion content in concrete up to $13 \mathrm{~mm}$ from the exposed face was $15 \mathrm{~kg} / \mathrm{m}^{3}$; that in the inner portions $137 \mathrm{~mm}$ thick $10 \mathrm{~kg} / \mathrm{m}^{3}$. Five faces except the under face (the exposed face of $200 \times 350 \mathrm{~mm}$ ) in specimens were sealed with the epoxy resin as shown in Figure 10. These three specimens were exposed to a wetting-drying repetitions (1 week) (immersion in water for 3 days, drying in 50\% R.H. atmosphere for 3 days and wetting in $90 \%$ R.H. for 1 days at $\left.40^{\circ} \mathrm{C}\right)$. After the completion of 8 wetting-drying repetitions, the concrete specimens were placed in an atmosphere at $40^{\circ} \mathrm{C}$ for 1 week, and then the total corrosion current densities between each element of steel bars were measured.

One specimen was the control. The other two concrete prisms were used for seeing the effects of $\mathrm{LiNO}_{2}$-containing mortar layers on the corrosion protection of steel bars and the effectiveness of zinc wires as a galvanic anode. Namely, concrete portions $13 \mathrm{~mm}$ thick in which steel bars were embedded, were removed, and then a zinc $(\phi 2 \mathrm{~mm})$ wire as a galvanic anode was arranged along steel bars in the specimen no. 3. Thereafter, the spaces occupied by old concrete $(25 \mathrm{~mm}$ thick) were filled with a mortar containing a large amount of $\mathrm{LiNO}_{2}\left(55 \mathrm{~kg} / \mathrm{m}^{3}\right)$. These three specimens were exposed to the same accelerated wetting-drying repetitions tests for 8 weeks as the untreated original concrete specimens.

At one week after the completion of the exposure tests, the total corrosion current densities between each element of steel bars were measured.

Figure 11 shows the maximum value of the total corrosion current densities between each element in steel bars in specimens before and after the application of $\mathrm{LiNO}_{2}$-containing mortar layer and a zinc galvanic anode. The maximum values of the total corrosion current densities in this figure refer to the maximum value among the ones obtained in each element of steel bars in divided parts. In Figure 11, it is seen that very large values of the total corrosion current density were measured for all of the three specimens without treatments after the completion of accelerated exposure tests (8 weeks). Namely, severe corrosion was in progress in steel bars embedded in the specimens. As seen in Figure 11, at the completion of the first accelerated exposure tests for 8 weeks, corrosion is found to actively progress on the upper half ( $\mathrm{N}$ (2)) in the inner steel bars. In particular, in no. 1 specimen without treatments (the control) (Figure 10), 


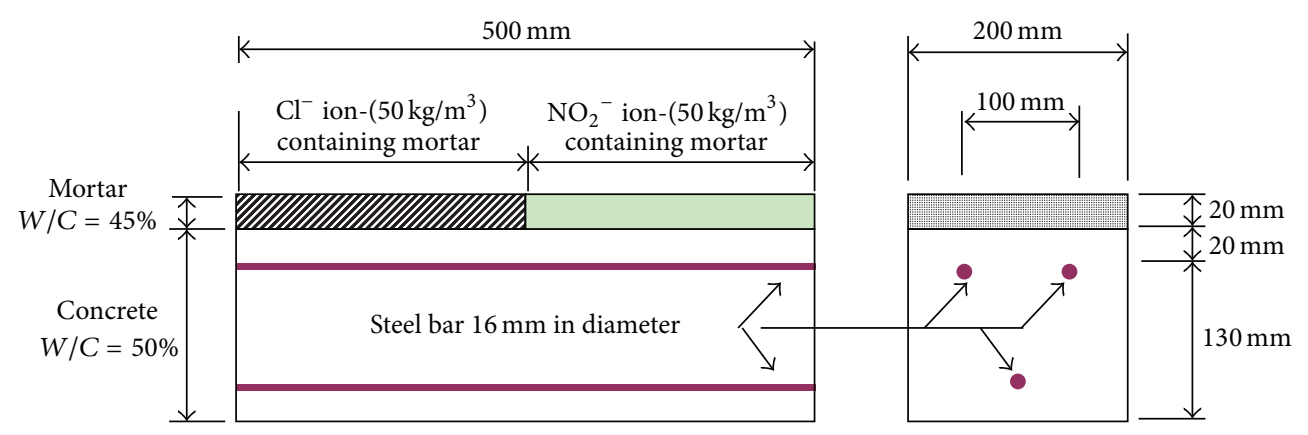

FIGURE 8: Concrete prisms for determining the penetration rate of $\mathrm{NO}_{2}{ }^{-}$and $\mathrm{Cl}^{-}$ions from mortars to concrete.

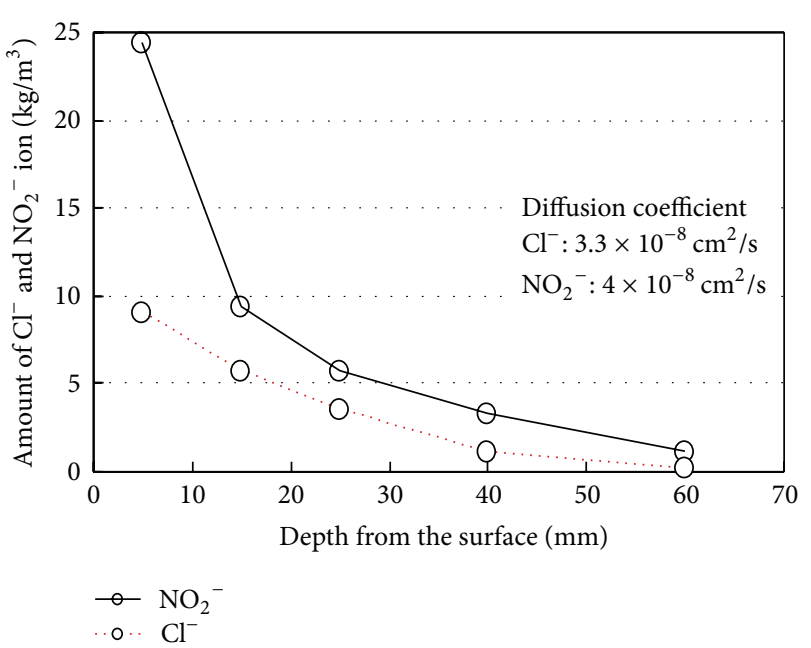

Figure 9: $\mathrm{NO}_{2}{ }^{-}$and $\mathrm{Cl}^{-}$ions profiles in concrete at the end of exposure tests.

very large corrosion current densities are measured on the lower half of the steel bars on the exposed face side $(\mathrm{H}$ (1)) after the completion of both the first and the second accelerated exposure testing (16 weeks). Figure 11 indicates that the corrosion current densities both on the upper and lower half of steel bars in the exposed face ( $\mathrm{H}$ (1), $\mathrm{H}$ (2) in no. 2 and no. 3 specimens) are greatly reduced by the treatments with $\mathrm{LiNO}_{2}$-containing mortars and zinc wires. This result indicates that the removal of $\mathrm{Cl}^{-}$ions containing portions at the end of the first accelerated exposure test for 8 weeks established corrosion protection environments around the steel bars. Furthermore, another important indication obtained from Figure 11 is that the corrosion current density in the lower half of steel bars in the inner side (N (1)) was reduced after the application of mortar layers with $\mathrm{LiNO}_{2}$. Thus, it is certain that $\mathrm{NO}_{2}{ }^{-}$ions moved from the mortar layers into the old concrete.

The corrosion current density on the upper half of steel bars in the inner portions in no. 2 specimen (N (2) decreased compared with that in the specimen without treatments. But the value of the corrosion current density itself is great. It is presumed that sufficient corrosion protection environments have not been established around steel bars. On the other hand, in specimen no. 3 with an attached zinc wire, the corrosion current densities in steel bars in both the upper and the lower half of the steel bars ( $N$ (1), N (2)) in the inner portions are smaller than those in specimen no. 2. In particular, the value of corrosion current density in the upper half in the steel bars in the inner portions in specimen no. 3 (N 2) is a third that in specimen no. 2. These results show that effects of a zinc wire as a galvanic anode appear at early stages.

In conclusion, it was confirmed that the arrangement of zinc wires along the steel bars as a galvanic anode was effective for protecting steel bars from corrosion in concrete structures in corrosive salt environments.

4.2. Conditions for Zinc Wires to Function as a Galvanic Anode. The formation of passivation films on the surface of zinc wires should be avoided for them to function as a galvanic anode. It is an essential condition that $\mathrm{pH}$ of the pore solution in concrete around steel bars is maintained above 13.3 [9]. Lithium nitrite is used as a corrosion inhibitor in the present corrosion protection method. The $\mathrm{pH}$ value in pore solutions in $\mathrm{LiNO}_{2}$-containing concrete increases with increasing amounts of the corrosion inhibitor. Pore solutions were extracted from mortar cylinder $(\phi 50 \times 100 \mathrm{~mm})$ containing an amount of $\mathrm{LiNO}_{2}$ of $55 \mathrm{~kg} / \mathrm{m}^{3}$ cured for 24 hours. Figure 12 shows a relationship between $\mathrm{NO}_{2}{ }^{-}$ion concentration and $\mathrm{pH}$ value in the pore solutions. Assuming that $\mathrm{pH}$ value is proportional to $\mathrm{NO}_{2}{ }^{-}$ion concentration in the pore solution in small ranges, the addition of about $40 \mathrm{~kg} / \mathrm{m}^{3}$ as $\mathrm{NO}_{2}{ }^{-}$ions to the mortars is required for $\mathrm{pH}$ value to be held about 13.3 .

It is assured that the process of the formation of corrosion products around zinc wires in concrete is not expansive.

\section{Practices in the Composite Corrosion Protection Method}

5.1. Overview of the Method. By using zinc wires as a galvanic anode, we can protect steel bars from corrosion even in the concrete structures exposed to corrosive saline environments since the completion of repair works. Thus, the extent of concrete to be removed can be limited to ranges of depths of cracks. 


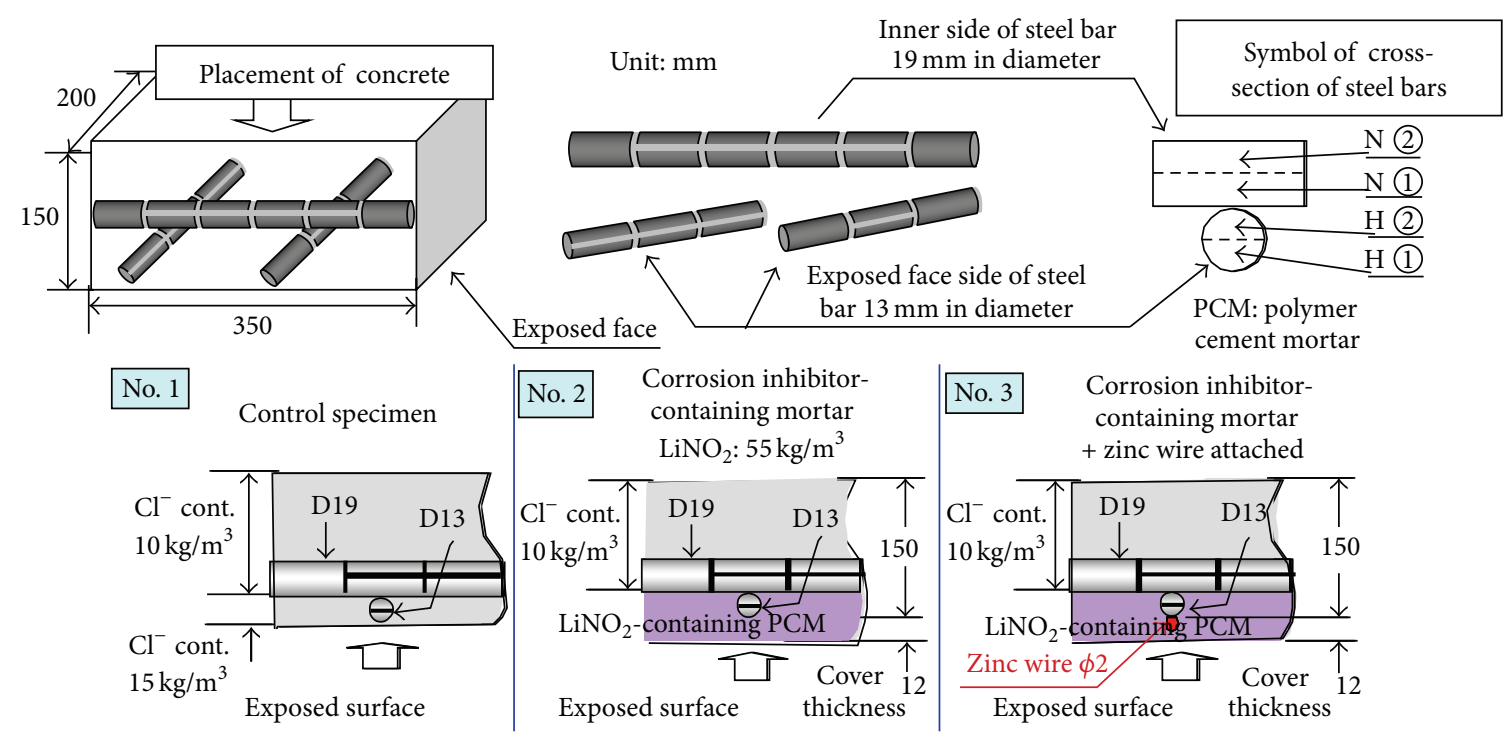

FIGURE 10: Specimens of exposure tests for confirming the effectiveness of zinc wire as a galvanic anode.

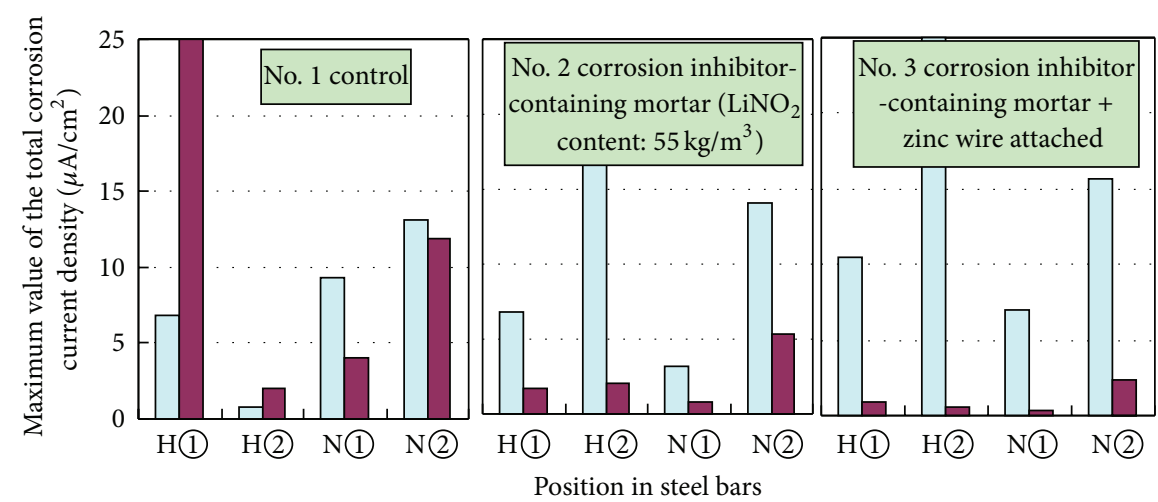

$\square$ After the accelerated exposure tests for 8 weeks

$\square$ Additional exposure tests for 8 weeks after the corrosion protection treatments

FIGURE 11: Maximum values of the total corrosion current densities between elements of steel bars before and after the application of $\mathrm{LiNO}_{2}$ containing mortar layers and a galvanic anode.

However, zinc wires used as a galvanic anode dissolve with time. Hence, the time for the zinc wires to effectively function as a galvanic anode is limited. On the other hand, in the corrosion protection method by the application of corrosion inhibitor-containing mortar layers, it takes long times for $\mathrm{NO}_{2}{ }^{-} / \mathrm{Cl}^{-}$molar ratio in atmospheres around steel bars to be higher than 0.8 . Therefore, the combined method of galvanic anode and nitrite penetration is based on the concept that the advantages of the exhibition of the function as a galvanic anode immediately after the application and the assurance of passivating atmospheres around steel bars for long periods by the penetration of nitrite are combined.

A flow chart of the design in the present method is given in Figure 13. It is possible to minimize the total amount of repair and renewal cost. Thus, this method can be applied to concrete members reaching accelerated corrosion or heavily damaged stages in which concrete covers have partly exfoliated. Thus, even if we apply this method to heavily damaged concrete members, steel bars in concrete will be passivated for long periods.

Figure 14 shows a photograph of a model made for better understanding of details of the combined corrosion protection technique. Firstly, zinc wires (2 4 $\mathrm{mm}$ in diameter) were arranged along steel bars (10 $\mathrm{mm}$ in diameter) and then connected to the inner steel bars on the upper side at a space of $125 \mathrm{~mm}$ to $300 \mathrm{~mm}$ by spot welding. After that, steel bars (19 $\mathrm{mm}$ in diameter) intersecting at right angles are covered by a large amount of $\mathrm{LiNO}_{2}$-containing mortar layers with 15 20 mm thick. Spaces above the $\mathrm{LiNO}_{2}$-containing mortar layers are filled with a corrosion inhibitor-free mortar for usual repair works. In relation to the use of a large amount of $\mathrm{LiNO}_{2}$-containing mortar, it was confirmed by experiments that mortars with a $\mathrm{LiNO}_{2}$ content of $70 \mathrm{~kg} / \mathrm{m}^{3}$ were workable enough to do practical works for filling portions removed in damaged concrete members. 


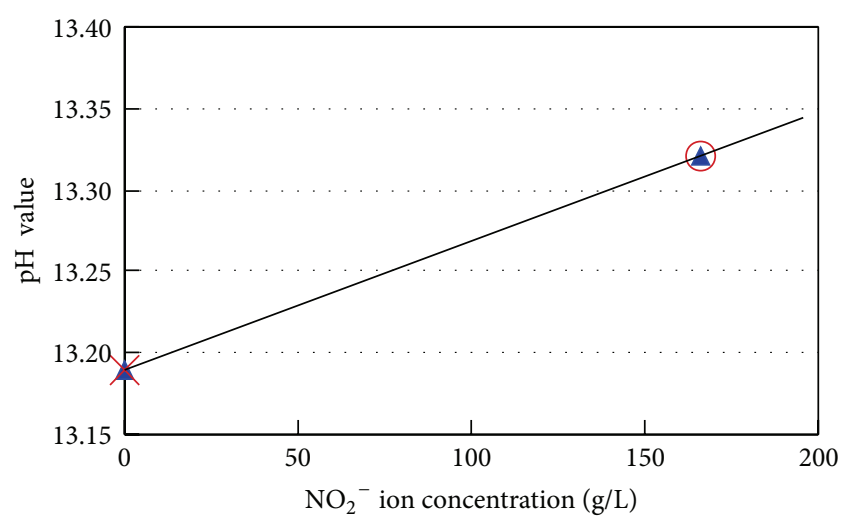

FIGURE 12: Relationship between $\mathrm{NO}_{2}{ }^{-}$ion concentration and $\mathrm{pH}$ in pore solutions in mortars.

5.2. Details of Design. As shown in Figure 13, firstly, the depth to be chipped, the amount of corrosion inhibitor, and the thickness of corrosion inhibitor-containing mortar layers are laid down. Secondly, the time up to the formation of an atmosphere for assuring the passivation of steel bars in existing concrete members is estimated. Finally, we judge the applicability of the present method to a damaged concrete member by verifying whether a zinc wire will function as a galvanic anode up to the attainment of the passivation of steel bars by nitrite ions.

The definite procedures are as follows.

(1) Values of $C_{0}$ (chloride ion concentration on the surface) and $D$ (apparent diffusion coefficient) are estimated from chloride ion concentration distributions in concrete.

(2) By using the $C_{0}$ and the $D$ values, the movement of $\mathrm{Cl}^{-}$ions, which remain behind in old concrete portions, and $\mathrm{NO}_{2}{ }^{-}$ions in a large amount of $\mathrm{LiNO}_{2}{ }^{-}$ containing mortar layers can be predicted by the finite difference method.

(3) It is possible to estimate when steel bars are passivated based on the $\mathrm{NO}_{2}{ }^{-} / \mathrm{Cl}^{-}$molar ratio.

(4) Effective period of zinc wires as a galvanic anode can be estimated from reductions in the mass of zinc wires by corrosion.

(5) Reductions in the mass of zinc wires are estimated from the value of corrosion current density in the steel bars after repair treatments using Faraday's law of electrolysis (see (1)):

$$
W=i \cdot t \cdot \frac{m}{2 F},
$$

where $W$ is the corrosion weight loss per unit surface area $\left(\mathrm{g} / \mathrm{cm}^{2}\right), i$ is the corrosion current density $\left(\mathrm{A} / \mathrm{cm}^{2}\right), t$ is the corrosion time $(\mathrm{s}), m$ is the molecular weight of zinc $(65.38 \mathrm{~g} / \mathrm{mol})$, and $F$ is the faraday constant $(96500 \mathrm{C} / \mathrm{mol})$.

(6) The life time $(L)$ of zinc wires is calculated by the use of (2). It is considered that the steel bars have been passivated at the end of the effective period. It is assumed that both the annual corrosion weight loss and the corrosion current density are zero at that time. Both the corrosion current density and the annual corrosion weight loss are also assumed to proportionally decrease time. A safety factor should be taken into consideration in actual calculations:

$$
L=\frac{Z}{(F s \times A s \times \Delta W / 2)},
$$

where $Z$ is the mass of zinc (g), Fs is the safety factor, $A s$ is the total surface area of steel bars $\left(\mathrm{cm}^{2}\right)$, and $\Delta W$ is the annual corrosion weight loss of zinc wires after application $\left(\mathrm{g} / \mathrm{cm}^{2} /\right.$ year).

If it is confirmed from the calculations that sufficient amounts of $\mathrm{NO}_{2}{ }^{-}$ion can penetrate into old concrete during the effective period of zinc wires as a galvanic anode, the combined method of corrosion protection will be applicable.

5.3. A Case Study of the Application. The case study is concerned with a degraded part of a 35-year-old RC bridge slab damaged by spraying of deicing salts (Figure 15). The nominal design strength and an apparent diffusion coefficient $(D)$ of the original concrete are $24 \mathrm{~N} / \mathrm{mm}^{2}$ and $3.0 \times 10^{-8} \mathrm{~cm}^{2} / \mathrm{s}$, respectively.

The details of steel bars used in the parts to be repaired are as follows.

Steel bars on the surface side in the under face of the slab are $25 \mathrm{~mm}$ in diameter and spaced $125 \mathrm{~mm}$; those on the inner side are $32 \mathrm{~mm}$ in diameter and spaced from 100 to $200 \mathrm{~mm}$; shear steel bars are $16 \mathrm{~mm}$ in diameter and spaced $125 \mathrm{~mm}$.

Concrete cover is $35 \mathrm{~mm}$ thick. Concentration distributions of chloride ions in near-surface regions on the under face side are provided in Figure 16. It is found from this figure that the chloride ion concentration at a position of steel bars is about $7 \mathrm{~kg} / \mathrm{m}^{3}$.

5.3.1. Details of Repair. A schematic diagram of the parts to be repaired is given in Figure 17. Deteriorated concrete parts $55 \mathrm{~mm}$ thick were removed. As a result, steel bars on the inner side in the under face were disclosed. We attached zinc wires ( $3 \mathrm{~mm}$ in diameter) on steel bars $(10 \mathrm{~mm}$ in diameter), as shown in Figure 17. The portions removed were restored by applying a $\mathrm{LiNO}_{2}$-containing mortar layer $\left(\mathrm{LiNO}_{2}\right.$ content: $70 \mathrm{~kg} / \mathrm{m}^{3}$ ), $20 \mathrm{~mm}$ thick, and a usual mortar layer, $35 \mathrm{~mm}$ thick.

5.3.2. Prediction of the Time up to the Attainment of a Passivating Condition. Distributions of $\mathrm{Cl}^{-}$and $\mathrm{NO}_{2}{ }^{-}$ion concentration immediately after repair and those predicted by the finite difference method are provided in Figure 16. A diffusion coefficient of $0.2 \times 10^{-8} \mathrm{~cm}^{2} / \mathrm{s}$ was used for both types of mortars in the analysis.

Figure 18 shows changes in $\mathrm{Cl}^{-}$and $\mathrm{NO}_{2}{ }^{-}$ion content, $\mathrm{NO}_{2}{ }^{-} / \mathrm{Cl}^{-}$molar ratio with time at a depth of $85 \mathrm{~mm}$ (the position of inner steel bars). It is found from this figure that 


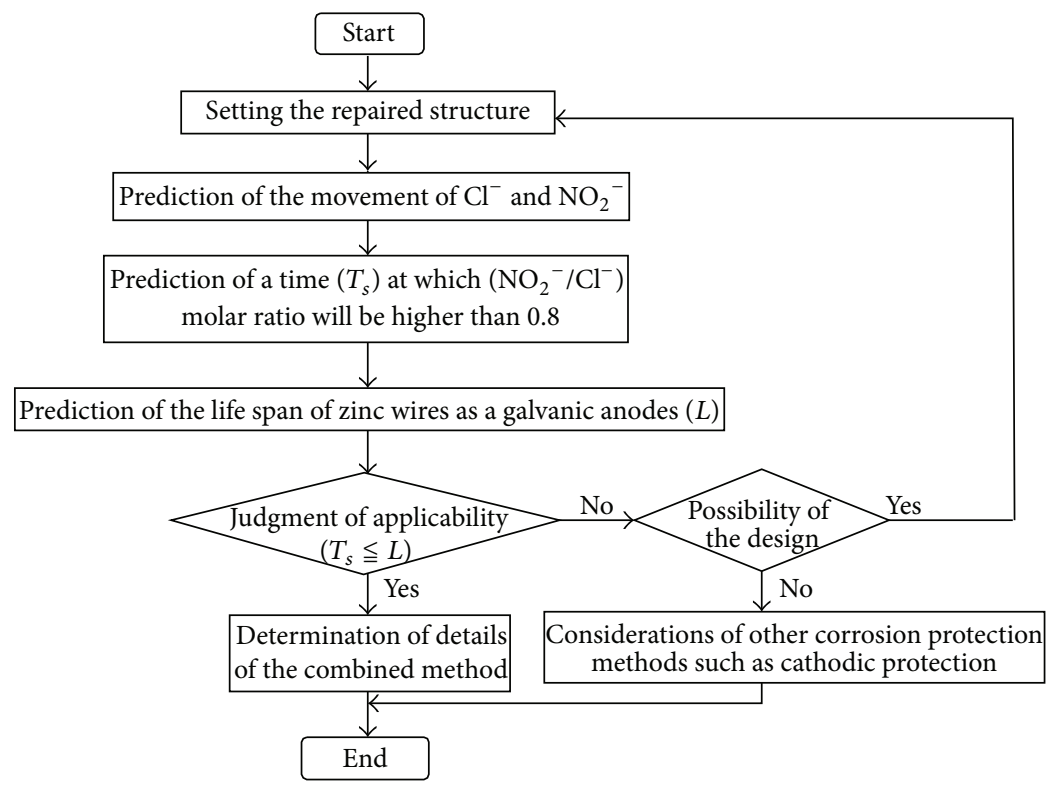

FIGURE 13: Flow chart of the design.

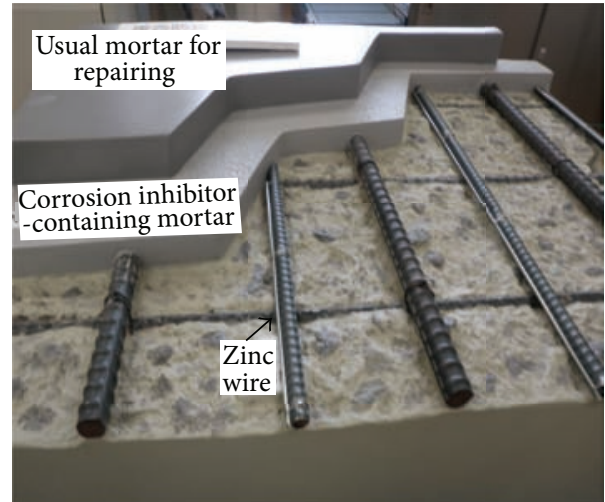

FIGURE 14: Model of details of the combined corrosion protection technique.

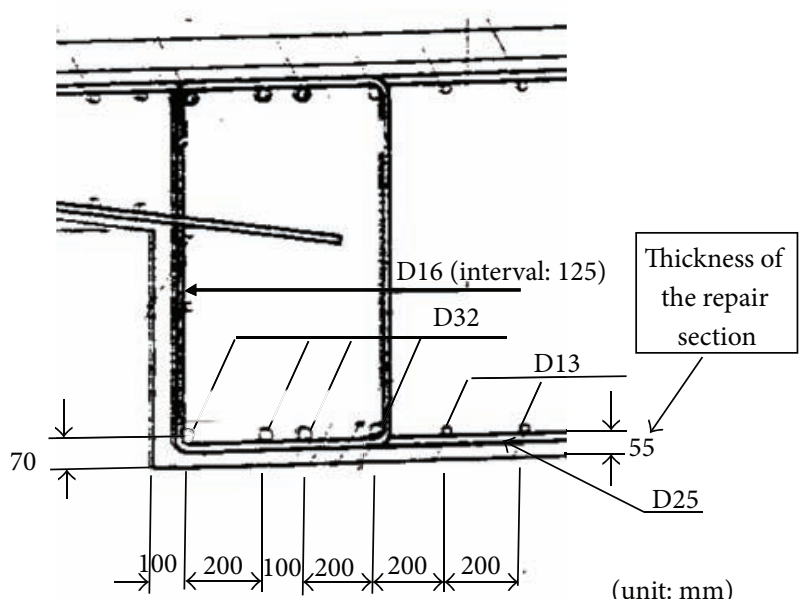

FIgURE 15: Part of the RC bridge slab.

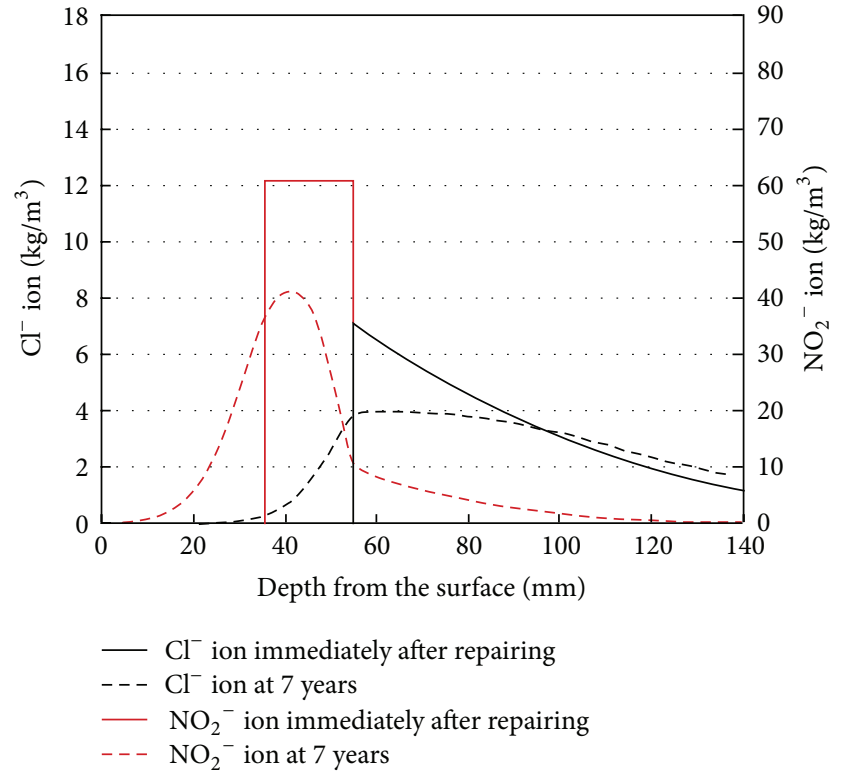

FIgURE 16: $\mathrm{Cl}^{-}$and $\mathrm{NO}_{2}{ }^{-}$ion concentration profiles immediately after repairing and their profiles predicted up to 7 years.

the time up to the attainment of a critical $\mathrm{NO}_{2}{ }^{-} / \mathrm{Cl}^{-}$molar ratio of 0.8 for passivating steel bars was 6.7 years.

5.3.3. Prediction of the Life Time of Zinc Wires. A zinc wire with $1 \mathrm{~m}$ long has a charge of surface area of approximately $0.17 \mathrm{~m}^{2}$ of steel bars to be passivated. Assuming that the corrosion current density of steel bars immediately after repair is $0.3 \mu \mathrm{A} / \mathrm{cm}^{2}$ (corrosion current density of a low to moderate level), a calculation by the use of (1) gives an annual corrosion weight loss of zinc of $0.0033 \mathrm{~g} / \mathrm{cm}^{2} \cdot$ year. The life 


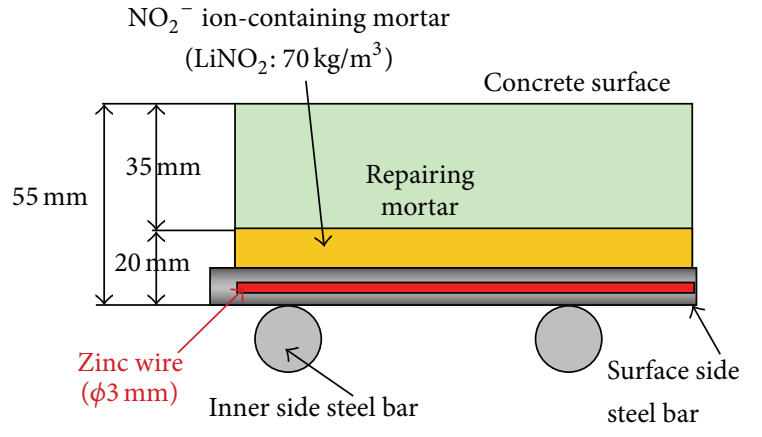

FIGURE 17: Schematic diagram of the parts repaired.

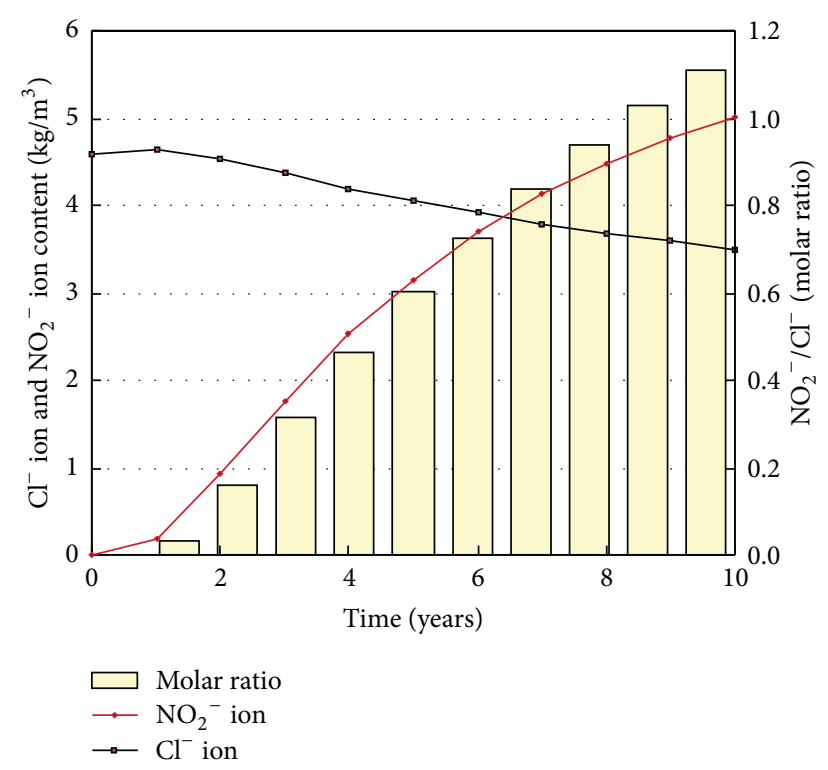

FIGURE 18: Changes in $\mathrm{Cl}^{-}$and $\mathrm{NO}_{2}{ }^{-}$ion content, $\mathrm{NO}_{2}{ }^{-} / \mathrm{Cl}^{-}$molar ratio with time at a depth of $85 \mathrm{~mm}$ (the position of inner steel bars).

time of zinc wires $L$ (years) in the case of arranging zinc wires with a diameter of $3 \mathrm{~mm}(0.505 \mathrm{~g} / \mathrm{cm})$ can be calculated by the use of (2). Assuming that the safety factor is 2 ,

$$
L=\frac{0.505}{2} \times\left(1700 \times\left(\frac{(0.0033+0)}{2}\right)\right)=9 \text { years } .
$$

As described above, the time up to the formation of an atmosphere for passivating steel bars was 6.7 years. Hence, the combined corrosion protection method is applicable to the repair of this deteriorated bridge slab.

5.3.4. Practical Works of Repair. A flow chart of the practical works of repair is provided in Figure 19. Cracked and exfoliated portions were removed with the hand breaker. However, in order to prevent concrete around steel bars from being damaged and to remove rust on the steel bars, it is preferable to conduct the chipping work by the water jet method. Chipping had been conducted until surfaces of steel bars on the inner side were disclosed.

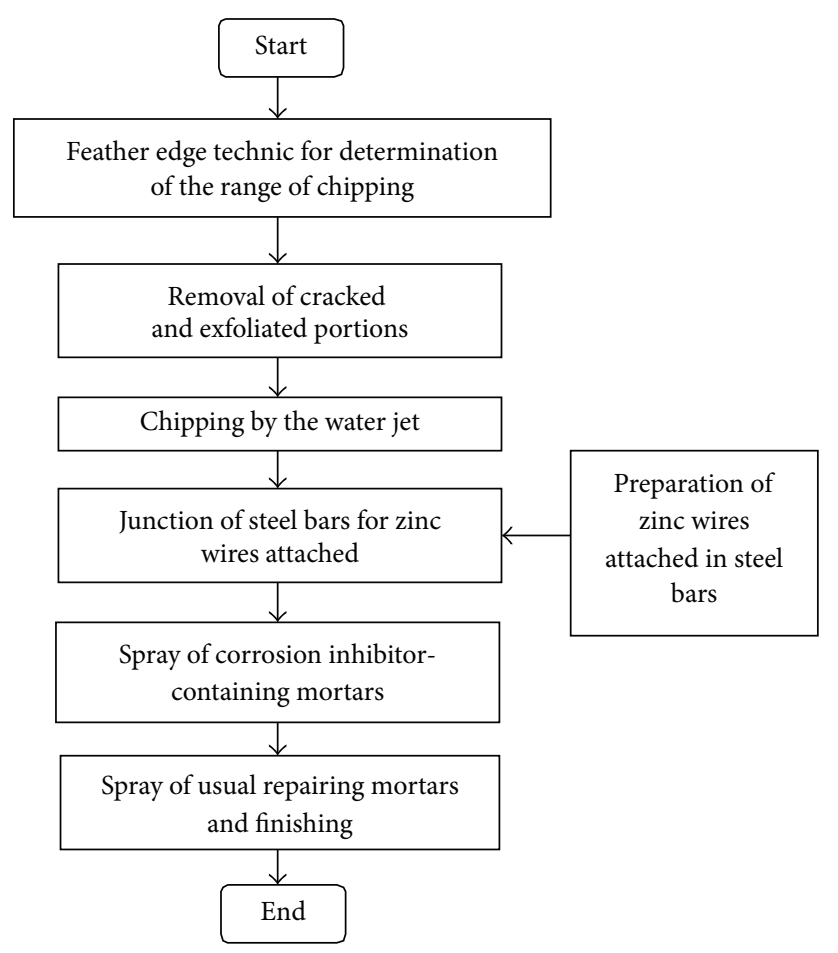

FIGURE 19: Flow chart of the practical works of repair.

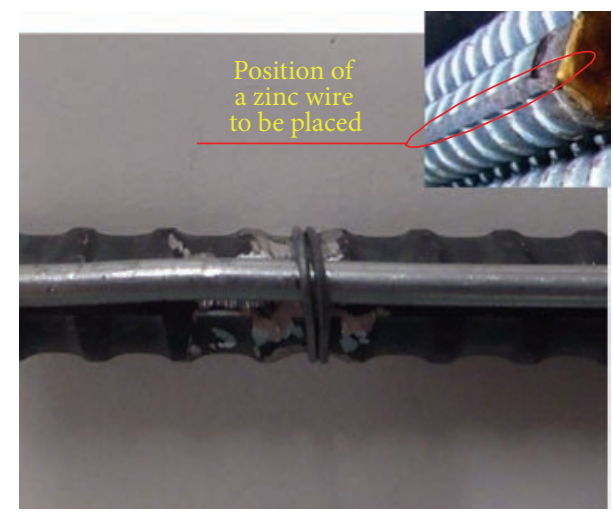

FIGURE 20: State of a zinc wire bound to steel bars.

In advance, zinc wires were bound to steel bars $10 \mathrm{~mm}$ in diameter at intervals of $200 \mathrm{~mm}$ in a factory and then installed in the construction site. Surfaces of steel bars attached to zinc wires should be ground and polished in advance. We placed a zinc wire along steel bars on the straight and tightly bound both using a mild steel wire (the electric resistance between surfaces: $0 \Omega$ ) with diameter of about $0.8 \mathrm{~mm}$ (Figure 20). It is important to make sure that the electric resistance between the bound mild steel wires, steel bars, and the zinc wires is less than $0.3 \Omega$.

In order to secure good galvanic electricity between zinc wire and steel bars, both were bound by spot welding at intersecting spots. To fix zinc wires around the central section of a corrosion inhibitor containing-mortar layer with a high $\mathrm{NO}_{2}{ }^{-}$ion concentration, zinc wires are positioned from 

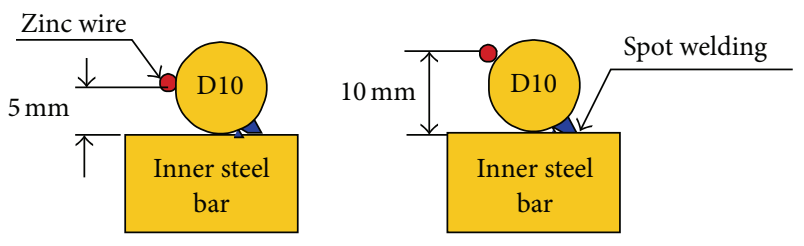

Figure 21: Position of a zinc wire attached.

$5 \mathrm{~mm}$ to $10 \mathrm{~mm}$ above the top of steel bars on the inner side, and then on the opposite side a zinc wire was welded to steel bars (see Figure 21).

\section{Summary and Conclusions}

The applicability of a corrosion protection method by the combination of galvanic anode and nitrite penetration to reinforced concrete members damaged by the chlorideinduced corrosion of steel bars were discussed. The major results obtained are summarized as follows.

(1) Many concrete structures have been damaged by externally supplied chloride-induced corrosion of steel bars. In these cases, it was proven by experiments that the corrosion was caused by the macrocells formed between the half of steel bars on the surface side (anode) and the other half and steel bars in the inner portions (cathode).

(2) A large amount of $\mathrm{LiNO}_{2}$-containing mortar layers applied to the surfaces of concrete members can supply concrete around steel bars with sufficient amounts of $\mathrm{NO}_{2}{ }^{-}$ions to prevent corrosion during the effective period of zinc wires as a galvanic anode.

(3) In a case study on a bridge slab damaged by externally supplied chloride-induced corrosion of reinforcement, the applicability of the combined method to the slabs was proven by calculating the amount of $\mathrm{NO}_{2}^{-}$ ions penetrated during the life time of zinc wires.

\section{Conflict of Interests}

The authors declare that there is no conflict of interests regarding the publication of this paper.

\section{References}

[1] J. Tritthart and P. F. G. Banfill, "Nitrite binding in cement," Cement and Concrete Research, vol. 31, no. 7, pp. 1093-1100, 2001.

[2] M. Kawamura, S. Tanikawa, R. N. Swamy, and H. Koto, "Pore solution composition and electrochemical behavior of steel bars in mortars with nitrite corrosion inhibitors," in Proceedings of the 5th CANMET/ACI International Conference on Superplasticizers and Other Chemical Admixtures in Concrete, pp. 35-53, Rome, Italy, 1997.

[3] V. T. Ngala, C. L. Page, and M. M. Page, "Corrosion inhibitor systems for remedial treatment of reinforced concrete. Part 1: calcium nitrite," Corrosion Science, vol. 44, no. 9, pp. 2073-2087, 2002.
[4] K. Y. Ann, H. S. Jung, H. S. Kim, S. S. Kim, and H. Y. Moon, "Effect of calcium nitrite-based corrosion inhibitor in preventing corrosion of embedded steel in concrete," Cement and Concrete Research, vol. 36, no. 3, pp. 530-535, 2006.

[5] N. S. Berke and M. C. Hicks, "Predicting long-term durability of steel reinforced concrete with calcium nitrite corrosion inhibitor," Cement and Concrete Composites, vol. 26, no. 3, pp. 191-198, 2004.

[6] H. Hirano, S. Miyazato, K. Yamamoto, and M. Takenouchi, "The explanation of salt damage mechanism progress on RC road bridge by spraying antifreeze agent," Proceedings of Japan Concrete Institute, vol. 29, no. 1, pp. 1005-1010, 2007 (Japanese).

[7] M. Aoyama, S. Hirano, D. Asae, and K. Torii, "Corrosion protection of steel bars in concrete in salt damage due to corrosion inhibitor mixing mortar," Proceedings of Japan Concrete Institute, vol. 27, no. 1, pp. 931-936, 2005 (Japanese).

[8] T. Ishikawa, S. Miyazato, M. Aoyama, and S. Hirano, "Development of repair method that combines the galvanic anode material and corrosion inhibitor for salt damage of the RC," Repair of Concrete Structures, vol. 10, pp. 29-36, 2010 (Japanese).

[9] A. Bentur, S. Diamond, and N. S. Berke, Steel Corrosion in Concrete, E \& FN Spon, London, UK, 1992. 

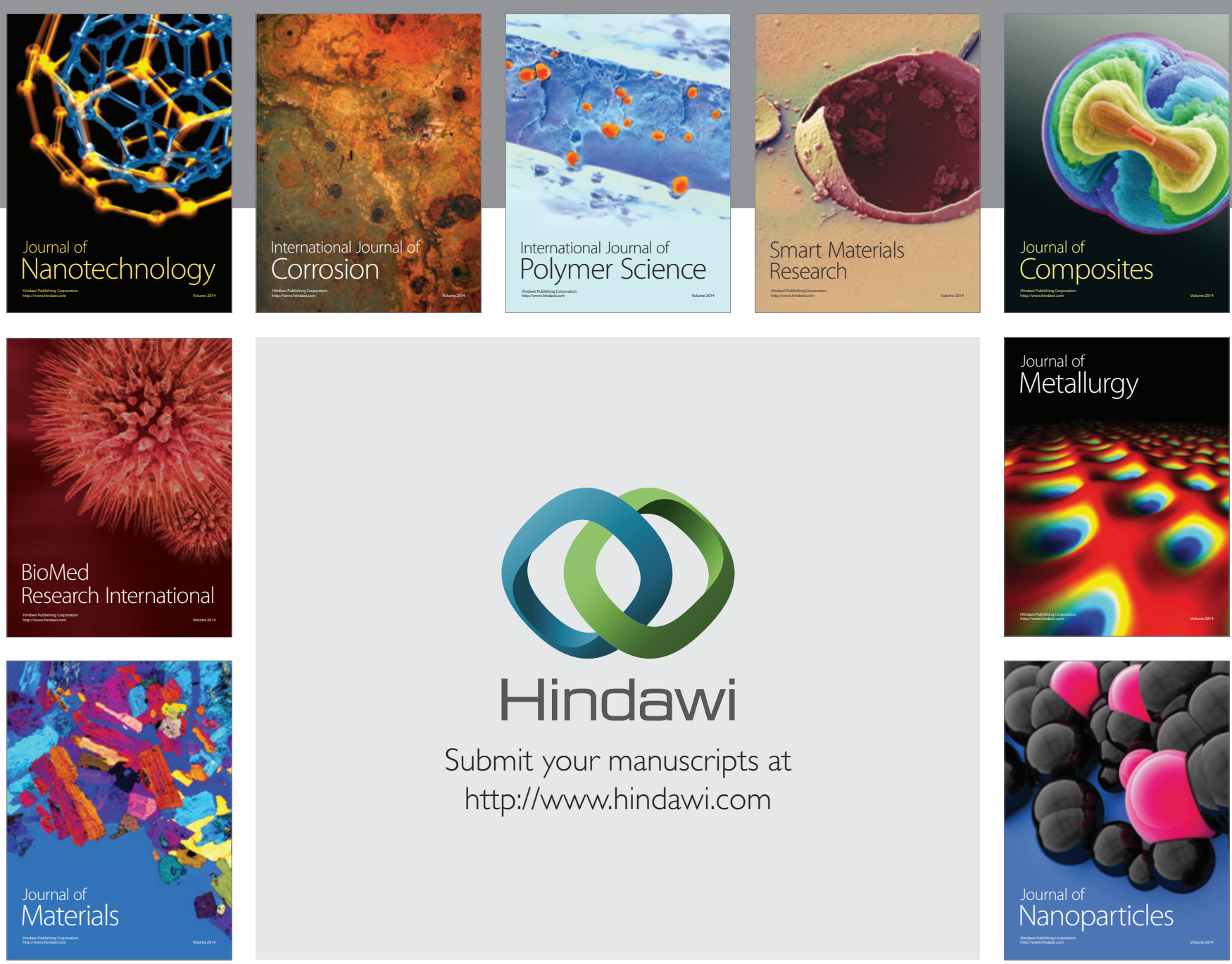

Submit your manuscripts at http://www.hindawi.com
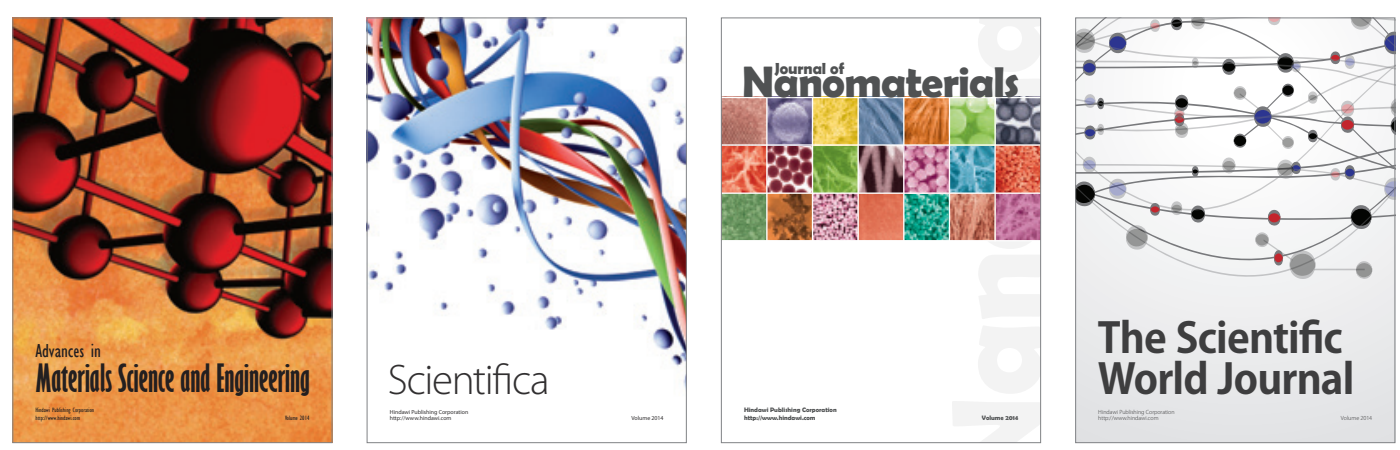

\section{The Scientific World Journal}
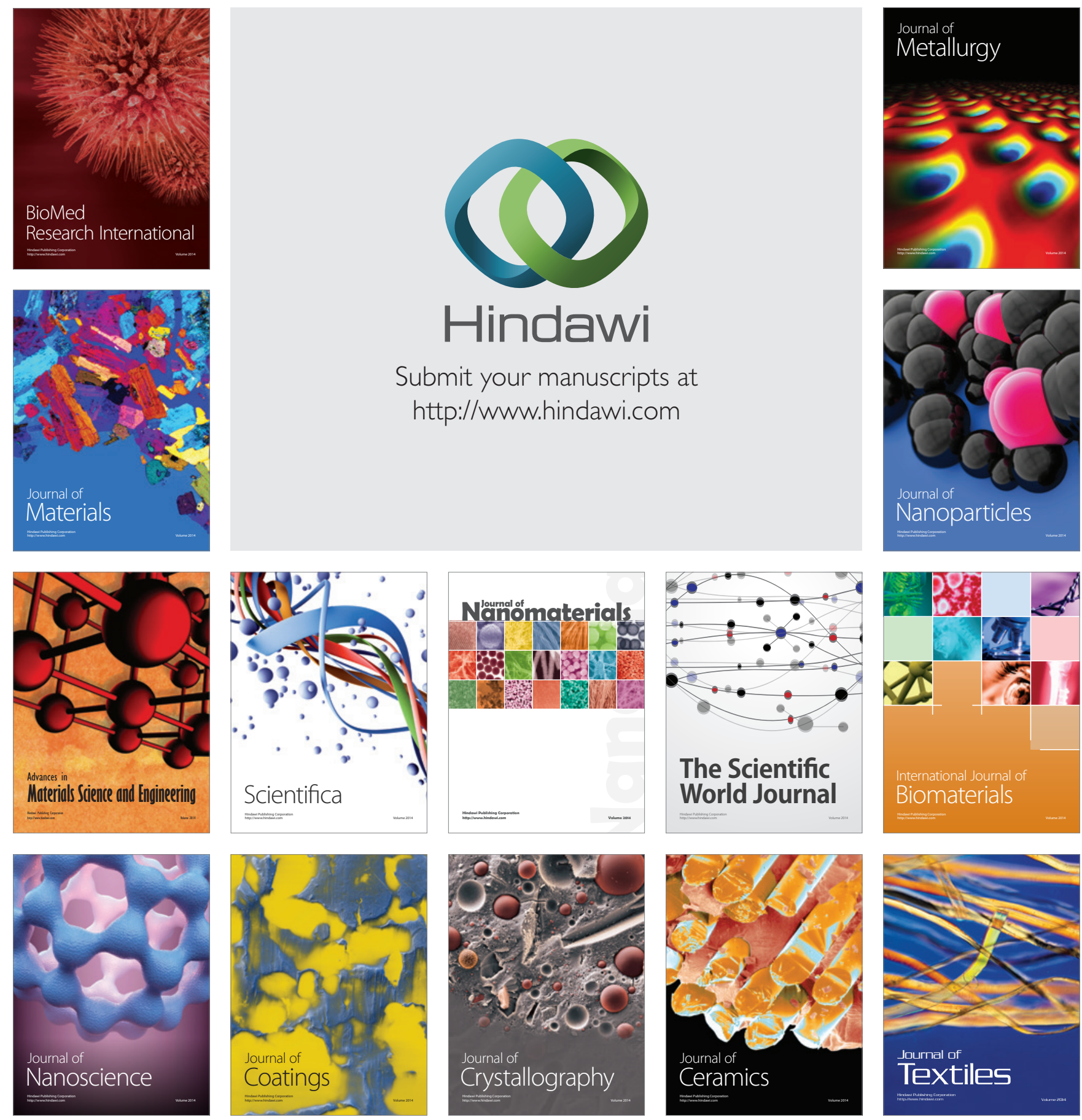